\title{
Microvascular complications and its predictors among type 2 diabetes mellitus patients at Dessie town hospitals, Ethiopia
}

\author{
Mohammed Abdu Seid ${ }^{1 *}$, Yonas Akalu², Yibeltal Yismaw Gela², Yitayeh Belsti ${ }^{2}$, Mengistie Diress²,
} Sofonias Addis Fekadu³, Baye Dagnew² and Mihret Getnet ${ }^{2}$

\begin{abstract}
Background: Diabetes mellitus is a serious metabolic disorder which becomes common in middle and low incomes countries since few decades. Microvascular complications include retinopathy, neuropathy and nephropathy all of which can lead to disability, dependency, accelerate their morbidity, and mortality. In Ethiopia, there is paucity data regarding this topic. Hence, this study aimed to assess prevalence of microvascular complications and its predictors among type 2 diabetes mellitus patients.

Methods: Cross-sectional study was conducted from February to March 2020 at Dessie town hospitals. We used simple random sampling to recruit study participants and pre-tested interviewer administered questionnaire to collect the data. Data was entered into Epi-Data 3.1 and exported to SPSS-23 for analysis. Binary logistic regression was done to select potential variables to be adjusted at $p \leq 0.25$. After running multivariable regression, variables with a $p$-value $\leq 0.05$ were declared as statistically significant.

Results: Three hundred and thirty-five type 2 DM patients participated in the study, of which $54.6 \%$ were males. One hundred and twenty-seven [37.9\% (95\% Cl 32.5\%-43.3\%)] of diabetes mellitus had at least one microvascular complications. These were retinopathy $24.8 \%$, nephropathy $16.1 \%$, and neuropathy $8.1 \%$. Age 60-87 years (AOR=2.76, $95 \% \mathrm{Cl} 1.02-7.46)$, duration of diabetes $>5$ years ( $\mathrm{AOR}=4.09$, 95\% $\mathrm{Cl} 2.40-6.96)$, mellitus and co-morbid hypertension $(\mathrm{AOR}=3.52,95 \% \mathrm{Cl}$ 2.09-5.95), were statistically significant.

Conclusions: In this study, diabetic microvascular complications are prevalent. Increasing the age of participants, longer duration of diabetes mellitus and co-morbid hypertension were independent predictors. Health workers should give emphasis for diabetes mellitus through early screening and health education, abrupt medication for aged patients with long duration of diabetes mellitus, and hypertension, and also early detection and management of microvascular complication.
\end{abstract}

Keywords: Microvascular complications, Predictors, Type 2 diabetes mellitus, Ethiopia

\footnotetext{
*Correspondence: mameabdu54@gmail.com

${ }^{1}$ Unit of Human Physiology, Department of Biomedical Science, College

of Health Sciences, Debre Tabor University, P. O. Box: 272, Debre Tabor, Ethiopia

Full list of author information is available at the end of the article
}

\section{Background}

Microvascular complications are sequels of diabetes mellitus following uncontrolled chronic hyperglycemia which includes diabetic nephropathy, neuropathy and retinopathy, that are caused by pathological changes in capillaries $[1,2]$. The time to develop microvascular permits use, sharing, adaptation, distribution and reproduction in any medium or format, as long as you give appropriate credit to the original author(s) and the source, provide a link to the Creative Commons licence, and indicate if changes were made. The images or other third party material in this article are included in the article's Creative Commons licence, unless indicated otherwise in a credit line to the material. If material is not included in the article's Creative Commons licence and your intended use is not permitted by statutory regulation or exceeds the permitted use, you will need to obtain permission directly from the copyright holder. To view a copy of this licence, visit http://creativecommons.org/licenses/by/4.0/. The Creative Commons Public Domain Dedication waiver (http://creativeco mmons.org/publicdomain/zero/1.0/) applies to the data made available in this article, unless otherwise stated in a credit line to the data. 
complications is much faster and common than macrovascular complication [3].

Diabetes mellitus (DM), commonest metabolic illness, is one of the major public health concern worldwide [4]. Diabetes burden has been rising more rapidly in low and middle income countries than in high income countries $[3,5]$, which is attributed to the effect of globalization, life style modification (change in diet type and pattern) and physical inactivity (being obese) [6].

Nowadays, the number of peoples living with diabetes increases rapidly and the disease become pandemic. Since few decades, the prevalence of type 2 diabetes has increase radically in all countries of the globe. It is about 422 million people have diabetes mellitus worldwide, and low-and middle-income countries are majorly the victims [5]. The disorder is also predicted to 578 million in 2030 and inflated to 700 million by the year 2045 [7]. In other words, nearly 1 in every 11 adults has diabetes globally, of which more than 3/4th is type $2 \mathrm{DM}$ [3]. Morbidity and mortality in chronic diabetes mellitus is now common that is more than four million people aged $20-79$ years were estimated to die from diabetes related complications [7]. Adequate data on tendencies of microvascular diabetes complications and other evolving complications are lacking and so that conclusions are incomplete [8].

Following the increase number of type 2 DM, its microvascular complication is rising proportionally and substantially [9]. Diabetic microvasculature is highly susceptible for damage due to chronic hyperglycemia and genetic predisposition, leading to complications of essential organs such as the kidneys, the eyes and the nervous system. Diabetic nephropathy is the foremost cause of serious renal disease, diabetic retinopathy (DR) is the amongst cause of blindness in diabetes population and that of diabetic neuropathy is the main attributing factor for diabetic foot ulcer and amputation $[9,10]$.

Almost all organs are affected and people suffer from serious morbidity and mortality due to type $2 \mathrm{DM}$ related complications. The commonest type $2 \mathrm{DM}$ microvascular complications are retinopathy, neuropathy and nephropathy that are present at the time of patient diagnosis [4, 11]. Chronic diabetes prone to lose more than half of the direct health costs following complications [12]. Indeed, they are eligible to develop disability, accelerate mortality and fail to avail work on regular basis due to the illness [1, $8,13]$.

Globally, around 1/5th (18.8\%) of type 2 diabetes mellitus developed microvascular complications [14], and this proportion was increased to $45 \%$ in middle east [15] and $47.8 \%$ in African diabetes [16]. In particular, different studies were conducted in different countries and revealed varying prevalence which is supported in USA 77\% [17], Brazil 41.6\% [18], China 57.5\% [19], Spain
25.2\% [20], Bangladesh 50.4\% [21], Greenland 68\% [12], Kuwait 61.6\% [22], Saudi Arabia 35.4\% [23], and Ghana $35.3 \%$ [24].

The emerging prevalence of diabetes and its complication also noted in Ethiopia. For instance, microvascular complication of type 2 diabetes is prevalent in Gondar, Ethiopia 20.4\% [25], wollega hospitals 31.2\% [26], Gurage zone $61 \%$ [27], Jimma university hospital $41.5 \%$ [28], Mettu Karl Referral Hospital 38.5\% [29], and Debre tabor Hospital 43.9\% [30].

Different literature showed that a number of factors are associated with microvascular diabetic complications. These factors could be grouped as socio-demographic factors (age, sex, and marital status), behavioral factors (obesity, diet) and clinical factors (glycemic control, and duration of diabetes, comorbidities (hypertension) and medication). In particular studies, being female [28, 31], age $[14,16,19,22,26,30,32,33]$, marital status (single or divorced) $[19,27]$, family history of diabetes mellitus [15, $26,28,31]$, longer duration of diabetic $[9,16,19,22,23$, $26,27,30-32,34]$, hypertension $[9,16,18-20,22,23,26$, $27,30,32,34,35]$, obesity [22, 27, 31], poor glycemic control $[18,22,25,27,28,33,34]$, adherence to diet $[16,22$, $35]$, mixed medication [26, 30] and insulin therapy only [22] were predictors for microvascular complications among type 2 diabetes mellitus patients.

In Ethiopia, people living with type $2 \mathrm{DM}$ ranged 2\% to $7 \%$ and its long term sequels are the major causes of morbidity and mortality besides to its economic crisis and social stigma [36]. Literature sources that showed factors exacerbating diabetic complications were too limited. Hence, this study was aimed to assess prevalence of microvascular complications and its predictors among type 2 diabetes mellitus patients in Dessie town hospitals.

\section{Methods and materials}

\section{Study design, setting and period}

Cross-sectional study was conducted from February to March 2020 at Dessie town hospitals. Dessie Town is found $400 \mathrm{~km}$ Northeast of Addis Ababa, the capital town of Ethiopia. Around fourteen thousand diabetes patients were served in a total of 5 hospitals. Diabetes patients have follow-up dates from Monday to Friday.

\section{Study population and eligibility}

Type 2 diabetes clients visiting the Hospitals at a regular base (every 3 months) as outpatient and available during the period of data collection were participants and eligible for this study. Those individuals living with diabetes who were critically ill or unconscious, gravid women at 2nd trimester and above were excluded. 


\section{Determination of sample size and sampling}

Sample size was estimated considering the following assumptions: $\mathrm{p}=0.705$ [33], $95 \% \mathrm{CI}$, and $5 \%$ margin of error. Hence, the calculated sample size was 319 and by adding $5 \%$ oversampling to account for non-respondents, we got a total of 335 . We used simple random sampling technique to recruit study participants and allocated proportionally for each hospital of Dessie town.

\section{Study variables}

- Dependent variable: Microvascular complications

- Independent variable: Socio-demographic factors (age, sex, residence, marital status, occupation), behavioral factors (physical activity, obesity, diet) and clinical factors (glycemic control, and duration of diabetes mellitus, comorbidities (hypertension) and anti-diabetic medication)

\section{Operational definitions}

Microvascular complications: Diabetes mellitus patients with one or more of the following complications: diabetic nephropathy, diabetic retinopathy, and peripheral neuropathy [14] of known diabetes or newly diagnosed diabetes.

Physical activity: Diabetes mellitus individuals who perform at least 150 min per week (3 days) of moderate intensity exercise regarded as Good otherwise poor physical activity [37].

Glycemic control level: It was good glycemic control when fast blood sugar (FBS) was below $130 \mathrm{mg} / \mathrm{dL}$ and above indicated value was regarded as poor [38].

Obesity: A client with body mass index (BMI) of $\geq 30 \mathrm{~kg} / \mathrm{m}^{2}$. It has three categories, category 1 (BMI: $\left.30-34.9 \mathrm{~kg} / \mathrm{m}^{2}\right)$, category 2 (BMI: $35-39.9 \mathrm{~kg} / \mathrm{m}^{2}$ ) and category 3 or extreme obesity ( BMI: $\geq 40 \mathrm{~kg} / \mathrm{m}^{2}$ ) [39].

Adherence to diet: Diabetes mellitus individuals adjust life style (diet) as recommended for more than 3 days in last seven consecutive days.

Data collection instrument, procedure and quality control Data were collected using a semi-structured interviewer administered questionnaire consisting sociodemographic factors, behavioral \& clinical predictors of microvascular complication in type 2 diabetes. These complications were diagnosed based on the physical, clinical, laboratorial and other requested findings and decision by the physician. Fundus ophthalmoscopy examination (the presence of neovascularization, hemorrhage spot, vitreous hemorrhage, microaneurysm, macular lesion and cotton wool spot) was done to diagnose diabetic retinopathy. For neuropathy, clinical assessment like history of numbness, paresthesia, tingling sensation and tests for vibration sensation was used. Likewise, symptoms such as swelling of feet, hands or eyes, urinary frequency and urgency, BP measurement and tests like protein in the urine, renal function tests and ultrasound were used diabetic nephropathy. Participants were interviewed and their medical chart was reviewed by trained data collectors to determine clinical and related factors. Clients' weight, height and blood pressure was measured in line with standard protocol. Data quality was assured by giving training prior to data collection and data collectors were supervised and applied measurements at least twice and the average was taken with the nearest value of 0.01 . Routinely, diabetes patients who had follow-up in diabetic clinic of each hospital were ordered to come to the next visit with their FBS result and data collectors used the newly FBS result. The data collection tools and instruments used were developed by for this study after reviewing different related literatures.

\section{Reliability and validity}

The Cronbach's alphas for this study was below 0.5 which is due to the questionnaires we used were self-developed and unstandardized. Content validity was ensured by pre-testing the data collection tool on $5 \%$ of diabetes. The tool was modified based on the observed findings from the pre-test result. Some questions having ambiguous meaning were rewritten for better understanding of study participants.

\section{Data processing and statistical analysis}

Data were cleaned, coded and entered into Epi-Data 3.1 and exported into SPSS version 23 for statistical analysis. Frequency tables with percentage, median, and interquartile range (IQR) was used to describe study findings. Variables with p-value $\leq 0.25$ in the binary logistic regression (age, marital status, residence, educational level, occupation, duration of diabetes, medication regimen, physical activity, hypertension and adherence to diet) were entered into multivariable logistic regression analysis. We used crude odds ratio (COR) and adjusted odds ratio (AOR) at $95 \%$ to determine the strength of association. Model fitness was verified by Hosmer and Lemeshow model fit and variance inflation factor tested variables multicollinearity. Lastly, variables with a p-value $\leq 0.05$ were declared as statistically significant.

\section{Results}

Socio-demographic characteristics of participants

A total of 335 type 2 diabetes mellitus were took part in the study. The median age of participants was 53 years (IQR: 45-60 years). More than half of the clients [183 (54.6\%)] were males. Majority of individuals [302 (90.1\%)] 
were married. Quarter of [78 (23.3\%)] them did not attend formal education and three-forth [259 (77.3\%)] individuals were urban dwellers (Table 1).

\section{Prevalence of microvascular diabetic complications}

In this study, the prevalence of at least one microvascular diabetic complications was $37.9 \%$ (95\% CI 32.5\%-43.3\%). Specifically, the prevalence of retinopathy, $24.8 \%$ (95\% CI 20.3-29.6\%), nephropathy, $16.1 \%$ (95\% CI $12.2-20.3 \%$ ), and neuropathy, $8.1 \%$ (95\% CI 5.1-11\%) among type 2 diabetes mellitus (Fig. 1).

\section{Behavioral and clinical characteristics of type 2 diabetes mellitus patients}

In this study, majority of individuals [269 (80.3\%)] and [205 (61.2\%)] had no family history of diabetes and diabetic education of $\leq 5$ years respectively. The drugs of choice for $223(66.6 \%)$ type 2 DM patients were oral drugs. Two hundred and eight (62.1\%) diabetes had inadequate physical activity. Majority of them, [297 (88.7\%)] and $[287(85.7 \%)]$ were non-obese and had poor glycemic control respectively. Only quarter [66 (19.7\%)] of individuals has adherence to diet and 231 (69.0\%) diabetes had co-morbid hypertension (Table 2).

Table 1 Socio-demographic characteristics of type-2 diabetes mellitus at Dessie town hospitals, Ethiopia $2020(n=335)$

\begin{tabular}{llcrc}
\hline Variable & Categories & Frequency (\%) & \multicolumn{2}{c}{$\begin{array}{c}\text { Microvascular } \\
\text { complications }\end{array}$} \\
\cline { 4 - 5 } & & & No & Yes \\
\hline \multirow{2}{*}{ Age } & 20-39 years & $37(11.0)$ & 30 & 7 \\
& 40-59 years & $195(58.2)$ & 139 & 56 \\
Sex & 60-87 years & $103(30.8)$ & 39 & 64 \\
\multirow{5}{*}{ Marital status } & Male & $183(54.6)$ & 118 & 65 \\
\multirow{5}{*}{ Residence } & Never married & $152(45.4)$ & 90 & 62 \\
& Married & $33(9.9)$ & 24 & 9 \\
& Urban & $302(90.1)$ & 184 & 118 \\
& Rural & $259(77.3)$ & 174 & 85 \\
& No read and write & $78(22.7)$ & 34 & 42 \\
& Grade 1-8 & $84(25.3)$ & 31 & 47 \\
& Grade 9-10 & $82(24.5)$ & 53 & 31 \\
\multirow{5}{*}{ Occupation } & Certificate and above & $91(27.2)$ & 65 & 23 \\
& Employed & $73(21.8)$ & 49 & 24 \\
& Private workers* & $117(34.9)$ & 83 & 34 \\
& Peasants & $37(11.0)$ & 18 & 19 \\
& House wife & $65(19.4)$ & 34 & 31 \\
& Others** & $43(12.9)$ & 24 & 19 \\
\hline
\end{tabular}

Private worker*: manufacturer, daily laborer, vehicle driver, mechanic, and wholesalers

Others**: unemployed and retiree

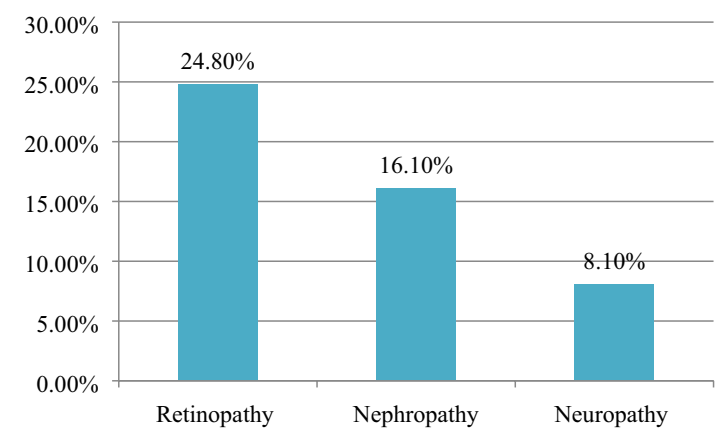

Fig. 1 Proportion of microvascular diabetic complications among type-2 diabetes mellitus at Dessie town hospitals, Ethiopia 2020 $(n=335)$

Predictors of microvascular complications among type 2 diabetes mellitus patients

In bi-variable logistic analysis, age, marital status, residence, educational level, occupation, duration of diabetes, medication regimen, physical activity, co-morbid hypertension and adherence to diet had $p$-value $\leq 0.2$ and hence were entered in to multivariable binary logistic analysis. In the final model, age of participants, duration of diabetes and co-morbid hypertension were statistically significant with the occurrence of microvascular complications.

Table 2 Behavioral and clinical characteristics of type-2 diabetes mellitus patients at Dessie town hospitals, Ethiopia 2020 $(n=335)$

\begin{tabular}{llrl}
\hline Parameters & Categories & Number & Percentage \\
\hline Family history of diabetes & Yes & 66 & 19.7 \\
& No & 269 & 80.3 \\
Duration of diabetes & $\leq 5$ years & 205 & 61.2 \\
& $>5$ years & 130 & 26.4 \\
Medication regimen & Drugs (OHA) & 223 & 66.6 \\
& Both oral \& insulin & 84 & 25.1 \\
Physical activity & Insulin only & 28 & 8.3 \\
& Good* & 127 & 37.9 \\
Obesity & Poor** & 208 & 62.1 \\
Hypertension & Yes & 38 & 11.3 \\
Adherence to diet & No & 297 & 88.7 \\
& Yes & 104 & 31.0 \\
Glycemic control & No & 231 & 69.0 \\
& Yes & 66 & 19.7 \\
& No & 109 & 84.5 \\
& Good & 48 & 14.3 \\
\hline
\end{tabular}

OHA oral hypoglycemic agent, Good* perform at least $150 \mathrm{~min} /$ week (3 days) of moderate intensity exercise, Poor ${ }^{* *}$ had not exercised at all or perform less than $150 \mathrm{~min} /$ week 
The odds of developing at least one diabetes microvascular complications for age groups $60-87$ yeas was 2.76 times $(\mathrm{AOR}=2.76$; 95\% $\mathrm{CI} 1.02-7.46)$ higher as compared to younger diabetes aged $20-39$ years. Participants who had a duration of diabetes more than 5 years was 4 times (AOR $=4.09$; 95\% CI 2.40-6.96) more likely to have microvascular complications in contrary to duration of diabetes 5 years or less. Moreover, diabetic clients with co-morbid hypertension were 3.52 times $(\mathrm{AOR}=3.52 ; 95 \%$ CI $2.09-5.95)$ more likely to acquire microvascular complications than non-hypertensive diabetes (Table 3).

\section{Discussion}

Nowadays, diabetes mellitus is alarmingly increasing chronic disease that has short and long term sequels if early medication and life-time modification is not sought. Likewise, the disorder is growing faster and becoming serious medical problem in Ethiopia. Microvascular complications could lead to visual, renal and neurological malfunction that all together results in sever morbidity, mortality and negative socio-economic consequences. Hence, identifying associated factors of microvascular complications is very crucial to halt its irreversible consequences.

In the current study, the overall prevalence of microvascular diabetic complications was $37.9 \%$. This proportion is in line with studies in Jimma, Ethiopia $41.5 \%$

Table 3 Multivariable binary logistic analysis for factors associated to microvascular complications among type-2 diabetes mellitus at Dessie town hospitals, Ethiopia $2020(n=335)$

\begin{tabular}{|c|c|c|c|c|c|}
\hline \multirow[t]{2}{*}{ Parameters } & \multirow[t]{2}{*}{ Categories } & \multicolumn{2}{|c|}{ Microvascular complications } & \multicolumn{2}{|l|}{ OR } \\
\hline & & No & Yes & COR $(99 \% \mathrm{Cl})$ & AOR $(95 \% \mathrm{Cl})$ \\
\hline \multirow[t]{3}{*}{ Age } & 20-39 years & 30 & 7 & 1 & 1 \\
\hline & $40-59$ years & 139 & 56 & $1.72(0.71-4.16)$ & $1.18(0.46-3.01)$ \\
\hline & $60-87$ years & 39 & 64 & $7.03(2.82-17.54)$ & $2.76(1.02-7.46)^{*}$ \\
\hline \multirow[t]{2}{*}{ Marital status } & Never married & 24 & 9 & 1 & 1 \\
\hline & Married & 184 & 118 & $1.71(0.76-3.80)$ & $0.72(0.24-2.11)$ \\
\hline \multirow[t]{2}{*}{ Residence } & Urban & 174 & 85 & 1 & 1 \\
\hline & Rural & 34 & 42 & $2.52(1.50-4.25)$ & $1.68(0.68-4.11)$ \\
\hline \multirow[t]{4}{*}{ Education } & No read and write & 31 & 47 & 1 & 1 \\
\hline & Grade 1-8 & 53 & 31 & $0.38(0.20-0.72)$ & $0.63(0.27-1.46)$ \\
\hline & Grade 9-10 & 59 & 23 & $0.25(0.133-0.45)$ & $0.46(0.17-1.20)$ \\
\hline & Certificate and above & 65 & 26 & $0.26(0.14-0.50)$ & $0.54(0.20-1.46)$ \\
\hline \multirow[t]{5}{*}{ Occupation } & Employed & 49 & 24 & 1 & 1 \\
\hline & Private worker & 83 & 34 & $0.83(0.44-1.57)$ & $0.53(0.23-1.24)$ \\
\hline & Peasants & 18 & 19 & $2.15(0.96-4.83)$ & $0.28(0.07-1.09)$ \\
\hline & House wife & 34 & 31 & $1.86(0.93-3.70)$ & $1.15(0.44-2.99)$ \\
\hline & Other & 24 & 19 & $1.61(0.74-3.50)$ & $0.37(0.12-1.101)$ \\
\hline \multirow[t]{2}{*}{ Duration of T2DM } & $\leq 5$ years & 160 & 45 & 1 & 1 \\
\hline & $>5$ years & 48 & 82 & $6.07(3.73-9.87)$ & $4.09(2.40-6.96)^{* *}$ \\
\hline Medication & Drugs $(\mathrm{OHA})$ & 158 & 65 & 1 & 1 \\
\hline \multirow[t]{2}{*}{ Regimen } & Mixed(oral \& insulin) & 40 & 44 & $2.67(1.59-4.48)$ & $1.24(0.56-2.390$ \\
\hline & Insulin only & 10 & 18 & $4.37(1.91-9.98)$ & $2.35(0.82-6.66)$ \\
\hline \multirow[t]{2}{*}{ Hypertension } & No & 150 & 81 & 1 & 1 \\
\hline & Yes & 58 & 46 & $4.93(3.06-7.95)$ & $3.52(2.09-5.95)^{* *}$ \\
\hline \multirow[t]{2}{*}{ Physical activity } & Good & 87 & 40 & 1 & 1 \\
\hline & Poor & 121 & 87 & $1.56(0.98-2.48)$ & $0.93(0.50-1.72)$ \\
\hline \multirow[t]{2}{*}{ Adherence } & No & 46 & 20 & 1 & 1 \\
\hline & Yes & 162 & 107 & $1.51(0.85-2.71)$ & $1.17(0.55-2.47)$ \\
\hline
\end{tabular}

OHA oral hypoglycemic agent, T2DM type 2 diabetes mellitus, $O R$ odds ratio, COR crude odds ratios, AOR adjusted odds ratios 
[28], Metu, Ethiopia 38.5\% [29], Ghana 35.3\% [24], Saudi Arabia 35.4\% [23], Brazil 41.6\% [18]. However, this finding is higher than studies in Gondar Ethiopia 20.4\% [25], Wollega, Ethiopia 31.2\% [26] and Spain 25.2\% [20]. On the other hand, this result is lower than studies in Debre Tabor, Ethiopia 43.9\% [30], Gurage, Ethiopia 61\% [27], Kuwait 61.6\% [22], Middle east 45\% [15], India 69\% [31], China 57.5\% [19], Bangladesh 50.4\% [21], Greenland, 68\% [12] and USA 77\% [17]. The difference might be related to sample size, accessibility and advancement of health institutions, patient's adherence to medication and practice to life style recommendations.

The current study concludes retinopathy $(24.8 \%)$ is the commonest microvascular complication, and on the other hand, neuropathy $(8.1 \%)$ is the least microvascular complication which is similar with findings from Debre Tabor, Ethiopia $(26.4 \%, 8.3 \%$ ) [30], Wollega, Ethiopia $(20.7 \%, 9.8 \%)$ [26], Saudi Arabia (14.8\%, 5.6\%) [23], and Brazil $(22.5 \%, 15.5 \%)$ [18] of retinopathy and neuropathy respectively.

In this study factors like increasing age of participants, duration of diabetes and co-morbid hypertension were significantly associated with the presence of microvascular complications.

The odds of developing at least one diabetes microvascular complications for age groups $60-87$ yeas was 2.76 times higher as compared to younger diabetes aged 20-39 years. This result is supported by findings from Debre Tabor [30], Wollega [26], Gondar [25], Saudi Arabia [23], Kuwait [22], Bangladesh [21], and China [19]. This is probably due to with advanced age, there combined effect of insulin resistance and loss of beta cells that brings hyperglycemia which in turn causes microvascular damage. Individuals diagnosed with diabetes at advanced age, may not survive long enough for microvascular complications to develop and/or to become clinically noticeable [40]. Moreover, being older is a powerful predictor of vascular damages. They also develop premature complications and death as compared to younger age [41].

Participants who had a duration of diabetes more than 5 years was 4 times more likely to have microvascular complications in contrary to duration of diabetes 5 years or less. This result agreed with studies in Ethiopia (Wollega [26], Gurage [27], Mettu [29]), Ghana [24], Saudi Arabia [23], Kuwait [22], Greenland [12], Greece [9], Brazil [18], and USA [17]. Longer diabetic duration was a potential risk factor for both microvascular diseases and macro-vascular disease independently $[16,18,42]$. In parallel to diabetes longer duration, there is chronic asymptomatic hyperglycemia that ends up with susceptible organ damage at diagnosis [36].

Diabetes clients with co-morbid hypertension were 3.52 times more likely to acquire microvascular complications than non-hypertensive diabetes. This is similar with findings of Mettu, Ethiopia [29], Kuwait [22], Greece [9], China [19], Spain [18], Bangladesh [21], and USA [17]. The possible justification is that high blood pressure accelerates the progress and development of microvascular complications due to increased intracellular hyperglycemia through up regulation of the glucose transporter 1 [43] so that increased plasma glucose level leads to damage of retinal blood vessels and glomeruli, also impair regulation of retinal perfusion [17]. Indeed, hypertension had direct effect on retinal endothelial cell and function that causes cell growth and vasoconstriction which eventually predisposes patients to vascular complications [21,44].

Unlike to this study, factors such as treatment regimen, poor physical activity and adherence to diet are significant for microvascular complication at Debre Tabor [30], Kuwait [22], Greenland [12], Bangladesh [21], and China [19].

As a limitation, the nature of cross-sectional study doesn't show case-effect relationship. Moreover, we used document review that lacks completeness for patients' profile. Also this study was an institutionbased so that it is unable to generalize the findings to the entire populations. Recall bias is an expected additional limitation.

\section{Conclusions}

The current study findings revealed that microvascular complications of diabetes were widespread particularly diabetic retinopathy that needs immediate intervention to halt its undesirable outcome of vision loss. Increasing age of participants, longer duration of diabetes and co-morbid hypertension were independent predictors of microvascular complications among type 2 diabetes mellitus. The study highlights the urgent need for strengthening and implementing of better diabetic management services at the area. Health professionals also should give more emphasis for diabetes mellitus through early screening and health education (primary prevention). Those aged diabetes patients with long duration of diabetes mellitus, and co-morbidities like hypertension should seek medication abruptly (secondary prevention). There is also a need to early detection and management of microvascular complication (tertiary prevention). Further better and high scale studies like prospective and clinical studies are highly recommended.

\section{Abbreviations}

AOR: Adjusted odd ratio; BMI: Body mass index; Cl: Confidence level; COR: Crude odd ratio; DM: Diabetes mellitus; FBS: Fasting blood sugar; SPSS: Statistical Package for Social Sciences. 


\section{Acknowledgements}

The authors are very thankful to forward their gratitude to the data collectors, supervisor, study subjects, Dessie town hospitals for their cooperation, and University of Gondar for approval.

\section{Authors' contributions}

MAS designed and implemented the study, collected data, performed statistical analysis, data interpretation, and drafted the manuscript. YYG, YBM, MDY and SAF developed tools, supervised data collection and first drafting. YA and BD contributed toward data analysis, report writing, drafting, and critically revising the paper, gave final approval of the manuscript to be published, and all authors agree to be responsible for all aspects of the work. All authors read and approved the final manuscript.

\section{Funding}

The authors did not gain any fund from anybody.

\section{Availability of data and materials}

In addition to the data and materials described in the manuscript, someone can get the dataset from the corresponding author MAS upon rational request.

\section{Declarations}

\section{Ethics approval and consent to participate}

The study protocol has been examined and approved by the ethical review committee of the School of Medicine, University of Gondar, Ethiopia. This study was done in line with the Helsinki's declaration. Prior to data collection, the aim and objectives of the study were explained to the study participants and written informed consent was received from each study individuals. Confidentiality is maintained throughout the study.

\section{Consent to publication}

Not applicable.

\section{Competing interests}

No competing of interests to declare.

\section{Author details}

${ }^{1}$ Unit of Human Physiology, Department of Biomedical Science, College of Health Sciences, Debre Tabor University, P. O. Box: 272, Debre Tabor, Ethiopia. ${ }^{2}$ Department of Human Physiology, School of Medicine, College of Medicine and Health Sciences, University of Gondar, Gondar, Ethiopia. ${ }^{3}$ Department of Optometry, College of Medicine and Health Sciences, University of Gondar, Gondar, Ethiopia.

\section{Received: 2 June 2021 Accepted: 2 August 2021}

Published online: 17 August 2021

\section{References}

1. Nam H. Cho RW. International Diabetes Association. IDF diabetes atlas. 9th edn; 2019. p. 93-100. www.diabetesatlas.org.

2. Vithian K. Microvascular complications: pathophysiology and management. Clin med. 2010;10(5):505-9.

3. Zheng Y, Ley SH, Hu FB. Global aetiology and epidemiology of type 2 diabetes mellitus and its complications. Nat Rev Endocrinol. 2017;14(2):8898. https://doi.org/10.1038/nrendo.2017.151.

4. A. S. Fauci, D. L. Kasper DLL et al. Harrison's: principles of internal medicine, 20th edn, vol. 112, The British Journal of Psychiatry. New York: McGraw-Hill; 2018. p. 2851-80. www.accessmedicine.com/harrisons.

5. World Health Organisation. Key fact sheets; 2021. Available from https:// www.who.int/news-room/fact-sheets/detail/diabetes.

6. Van Dieren S, Beulens JWJ, Van Der Schouw YT, Grobbee DE, Neal B. The global burden of diabetes and its complications: an emerging pandemic. Eur J Cardiovasc Prev Rehabil. 2010;17(SUPPL. 1):3-8.

7. Saeedi P, Petersohn I, Salpea P, Malanda B, Karuranga S, Unwin N, et al. Global and regional diabetes prevalence estimates: results from the International Diabetes Federation Diabetes Atlas, 9th edition. Diabetes
Res Clin Pract. 2019;157:107843. https://doi.org/10.1016/j.diabres.2019. 107843.

8. Harding JL, Pavkov ME, Magliano DJ, Shaw JE, Gregg EW. Global trends in diabetes complications: a review of current evidence. Diabetologia. 2019;62:3-16.

9. Faselis C, Katsimardou A, Imprialos K, Deligkaris P, Kallistratos M, Dimitriadis K. Microvascular complications of type 2 diabetes mellitus. Curr Vasc Pharmacol. 2019;18(2):117-24.

10. Stolar M. Glycemic control and complications in type 2 diabetes mellitus. Am J Med. 2010;123(3 SUPPL.):S3-11. https://doi.org/10.1016/j.amjmed. 2009.12.004.

11. World Health Organisation. Global report on diabetes mellitus; 2018. p. 11-4. http://www.who.int.

12. Pedersen ML, Jacobsen JL, Lynge AR. Micro-and macrovascular complications among Greenlanders and Danes with type 2 diabetes mellitus in Nuuk, Greenland Micro- and macrovascular complications among Greenlanders and Danes with type 2 diabetes mellitus in Nuuk. Greenland Int J Circumpolar Health. 2010;69:195-207.

13. Girach A, Vignati L. Diabetic microvascular complications - can the presence of one predict the development of another? J Diabetes Complicat. 2006;20:228-37.

14. Kosiborod M, Gomes MB, Nicolucci A, Pocock S, Rathmann W, Shestakova MV, et al. Vascular complications in patients with type 2 diabetes: prevalence and associated factors in 38 countries ( the DISCOVER study program). Cardiovasc Diabetol. 2018. https://doi.org/10.1186/ s12933-018-0787-8.

15. Cheema S, Maisonneuve P, Zirie M, Jayyousi A, Alrouh H, Abraham A, et al. Risk factors for microvascular complications of diabetes in a high-risk middle east population. J Diabetes Res. 2018;2018:1-8.

16. U. S. Jasper MCO and EBP. Prevalence and clinical pattern of acute and chronic complications in African diabetic patients. Br J Med Med Res. 2014;4(30):4908-17.

17. Ramanathan RS. Correlation of duration, hypertension and glycemic control with microvascular complications of diabetes mellitus at a tertiary care hospital. Integr Mol Med. 2017;4(1):1-4.

18. Cardoso CRL, Salles GF. Predictors of development and progression of microvascular complications in a cohort of Brazilian type 2 diabetic patients B. J Diabetes Complicat. 2008;22:164-70.

19. Li J, Chattopadhyay K, Xu M, Chen Y, Hu F, Chu J, et al. Prevalence and associated factors of vascular complications among inpatients with type 2 diabetes. PLoS ONE. 2020. https://doi.org/10.1371/journal.pone.02351 61.

20. Javier F, Fernández C, Moreno I, Pérez-jáuregui CDG, Silveira B, González T, et al. Microvascular complications and Microvascular complication and risk factors in patients with type 2 diabetes. Elsevier Espania. 2011;58(4):1-6.

21. Akter P, Hoque S, Begum T, Humaira S, Ahmed Z. Diabetes \& metabolic syndrome: clinical research \& reviews microvascular complications and their associated risk factors in type 2 diabetes mellitus. Diabetes Metab Syndr Clin Res Rev. 2017. https://doi.org/10.1016/j.dsx.2017.04.007.

22. El-shazly MK, Al-shammeri RM, Moula AMA, Ismail AE, Ismail WA. Prevalence and factors associated with chronic diabetic complications among patients attending primary health care, a multi-centric study in Kuwait. Chronic Diabet Complicat. 2010;46(2):1-12.

23. Alaboud AF, Tourkmani AM, Alharbi TJ, Alobikan AH, Abdelhay O, Al Batal SM, et al. Microvascular and macrovascular complications of type 2 diabetic mellitus in Central, Kingdom of Saudi Arabia. Saudi Med J. 2016;37(12):1408-11.

24. Annani-akollor ME, Addai-mensah O, Fondjo LA, Sallah L, Owiredu E,

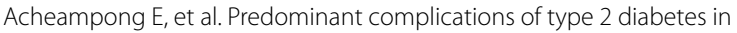
Kumasi : A 4-year retrospective cross-sectional study at a teaching hospital in Ghana. Medicina (B Aires). 2019;55(125):1-11.

25. Fasil $A B$, Belete $A M$. Glycemic control and diabetes complications among diabetes mellitus patients attending at University of Gondar Hospital, Northwest Ethiopia. Diabetes Metab Syndr Obes Targets Ther. 2019;12:75-83.

26. Korsa AT, Genemo ES, Bayisa HG, Dedefo MG. Diabetes mellitus complications and associated factors among adult diabetic patients in selected hospitals of west ethiopia diabetes mellitus complications and associated factors among adult diabetic patients in selected hospitals of West Ethiopia. Open Cardiovasc Med J. 2019;13:41-8. 
27. Gebre BB, Assefa ZM. Magnitude and associated factors of diabetic complication among diabetic patients attending Gurage zone hospitals. South West BMC Res Notes. 2019;12(780):1-6. https://doi.org/10.1186/ s13104-019-4808-9.

28. An T. Major microvascular complications and associated risk factors among endocrinology \& metabolic syndrome major microvascular complications and associated risk factors among diabetic outpatients in Southwest Ethiopia. Endocrinol Metab Syndr. 2017;6(4):1-10.

29. Sheleme T, Mamo G, Melaku T, Sahilu T. Prevalence, patterns and predictors of chronic complications of diabetes mellitus at a large referral hospital in Ethiopia: a prospective observational study. Diabetes Metab Syndr Obes Targets Ther. 2020;13:4909-18.

30. Ayele WM. Chronic diabetic complications and associated factors among people with type-2 diabetes mellitus in Debretabor Hospital. Northwest J Diabetes Metab. 2018;11(5):1-6.

31. Bruce MSP, Mallika MCV. Prevalence of complications of diabetes among patients with diabetes mellitus attending a tertiary care centre in Tamil Nadu. Semicond Sci Technol. 2019;6(4):1452-6.

32. Arambewela MH, Somasundaram NP, Buddhi H, Ranjan P, Kumbukage MP, Mudiyanselage $P$, et al. Prevalence of chronic complications, their risk factors, and the cardiovascular risk factors among patients with type 2 diabetes attending the diabetic clinic at a tertiary care hospital in Sri Lanka. J Diabetes Res. 2018;2018:1-11.

33. Abejew AA, Belay AZ, Kerie MW. Diabetic complications among adult diabetic patients of a tertiary hospital in Northeast Ethiopia. Adv Public Health. 2015. https://doi.org/10.1155/2015/290920.

34. Fawwad A, Mustafa N, Zafar AB, Khalid M. Incidence of microvascular complications of type 2 diabetes: a 12 year longitudinal study from Karachi-Pakistan. Pak J Med Sci. 2018;34(5):1058-63.

35. Ahmed MB, Yirdachew E, Tefera G. iMedPub journals diabetic complications among follow-up patients: a cross-sectional study at Jimma university specialized hospital diabetic clinic keywords: background. J Clin Mol Endocrinol. 2018;3(45):1-7.

36. Eppens MC, Craig ME, Cusumano J, Hing S, Chan A, et al. Prevalence diabetes complication in adolescents with type 2 compared with type 1 diabetes. Diabetes Care. 2009;29:1300-6.
37. Colberg SR, Sigal RJ, Fernhall B, Regensteiner JG, Blissmer BJ, Rubin RR, et al. Exercise and type 2 diabetes: the American college of sports medicine and the American diabetes association: joint position statement. Diabetes Care. 2010;33(12):e150.

38. Care M. Standards of medical care in diabetes-2020. Clin Appl Res Educ. 2020;43:s66-74

39. Hales CM, Fryar CD, Carroll MD, Freedman DS, Ogden CL. Trends in Obesity and Severe Obesity Prevalence in US Youth and Adults by Sex and Age, 2007-2008 to 2015-2016. JAMA 2018;319(16):1723-25.

40. Zoungas S, Woodward M, Li Q, Cooper ME, Hamet P, Harrap S, et al. Impact of age, age at diagnosis and duration of diabetes on the risk of macrovascular and microvascular complications and death in type 2 diabetes. Diabetologia. 2014;57:2465-74.

41. Nanayakkara N, Curtis AJ, Heritier S, Gadowski AM, Pavkov ME, Kenealy T, et al. Impact of age at type 2 diabetes mellitus diagnosis on mortality and vascular complications: systematic review and meta-analyses. Diabetologia. 2021;64:275-87. https://doi.org/10.1007/s00125-020-05319-w.

42. Li L, Ji L, Guo X, Ji Q, Gu W, Zhi X, et al. Prevalence of microvascular diseases among tertiary care Chinese with early versus late onset of type 2 diabetes. J Diabetes Complicat. 2015;29(1):32-7. https://doi.org/10.1016/j. jdiacomp.2014.08.010.

43. Bui HDT, Jing X, Lu R, Chen J, Ngo V, Cui Z, Yuanyuan Liu CL, Ma J. Prevalence of and factors related to microvascular complications in patients with type 2 diabetes mellitus in Tianjin, China. Ann Transl Med [Internet]. 2019;7(14):1-10. Available from: https://doi.org/10.21037/atm.2019.06.08

44. Avogaro A, Fadini GP. Microvascular complications in diabetes: a growing concern for cardiologists. Int J Cardiol. 2019;291:29-35. https://doi.org/10. 1016/j.ijcard.2019.02.030.

\section{Publisher's Note}

Springer Nature remains neutral with regard to jurisdictional claims in published maps and institutional affiliations.
Ready to submit your research? Choose BMC and benefit from:

- fast, convenient online submission

- thorough peer review by experienced researchers in your field

- rapid publication on acceptance

- support for research data, including large and complex data types

- gold Open Access which fosters wider collaboration and increased citations

- maximum visibility for your research: over 100M website views per year

At BMC, research is always in progress.

Learn more biomedcentral.com/submissions 